\title{
Structure and Properties of Polymers Prepared by Polymerization of 2,2-Dimethyl-1,3-Propandiol and $\varepsilon$ - Caprolactone Monomer
}

\author{
I Made Arcana*, M. Hasan, Shinta Dewi Anggraini, Asti Ardhyo Febrianti, \& \\ Aditya Ardana \\ Inorganic and Physical Chemistry Research Division, Faculty of Mathematic and \\ Natural Sciences, Institut Teknologi Bandung, Jalan Ganesha No. 10, Bandung 40132, \\ Indonesia, Fax No. : 62-22-2504154, E-mail Address : arcana@chem.itb.ac.id
}

\begin{abstract}
Poly( $\varepsilon$-caprolactone) (PCL) is very attractive synthetic polymer due to its properties, such as a high permeability, the lack of toxicity, and also biodegradability. However, it has limited application because of low melting point $\left(60{ }^{\circ} \mathrm{C}\right)$, high crystallinity, and brittleness. The aim of the experiments is designed to improve the properties of PCL by formation of their polymers with 2,2-dimethyl-1,3-propandiol monomers with various chain length as a raw material to prepare poly(urethane-ester). These polymers were synthesized by a ring-opening polymerization of 2,2-dimethyl-1,3-propandiol and $\varepsilon$-caprolactone monomers in various composition in the presence of 1-hydroxy-3-chlorotetraisobuthyldistanoxane as a catalyst. Polymers were characterized by analysis of functional groups (FTIR), microstructure $\left({ }^{1} \mathrm{H}\right.$ and ${ }^{13} \mathrm{C}$ NMR), viscosity, hydroxyl number, and also melting point of polymers (DSC). Based on the structure analysis indicate that polymerization of 2,2-dimethyl-1,3-propandiol and $\varepsilon$-caprolactone monomers produced polymers with various molecular weights, which depend on the ratio of e-caprolactone / 2,2-dimethyl-1,3propandiol used in polymerization. The reactivity of CL monomer decreases to the active site of polymers with longer chain size. The melting points of polymers increase with the increasing of $\varepsilon$-caprolactone composition used in polymerization, whereas hydroxyl number decreases.
\end{abstract}

Keywords: block polymer; caprolactone; distannoxane; propandiol; properties.

\section{Introduction}

Increasing volumes of synthetic polymers are manufactured for various applications, mostly for packaging materials. Disposal of the used polymers has been accumulated under the land surface. Unlike natural polymers, most synthetic polymers can not be decomposed by microorganisms, hence the landfill approach becomes inefficient, and other plastics waste management should be found. New techniques have been developed to obtain environmentally friendly polymers. 
Biopolyesters (PHAs) (poly(3-hydroxyalkanoates) and other synthetic linear polyesters, such as polylactide (PLA), polycaprolactone (PCL), and poly(3hydroxybutyrate) (PHB), are very interesting because of their biocompatibility, biodegradability, and permeability [1]. However, practical applications of these polyesters have often been limited by its brittleness and crystallinity. These materials need chemical modification to improve their mechanical and viscoelastic properties for some medical and industrial applications. Chemical modifications have been achieved through the copolymerization, blending, branching, and cross-linking of biodegradable polyesters [2]. Several researchers have attempted to modify and improve the degradability and mechanical property of PCL and PLA through copolymerization, such as poly(caprolactone-co-lactide acid) $\mathrm{P}(\mathrm{CL}-\mathrm{co}-\mathrm{LA})$ and poly(lactide acid-blockethylene glycol) P(LA-block-EG). These polymers generally exhibit good mechanical strength, biocompatibility, and biodegradability [3,4]. Other researcher has synthesized block copolymer of polycaprolactone-polyethylene glycol (PCL-block-PEG) by copolymerization of $\varepsilon$-caprolactone with PEG in the presence of a common esterification catalyst of tetra-n-butyl titanate Ti(n$\mathrm{Bu})_{4}$ [5]. The degradation of this copolymer increased with decreasing crystallinity of the copolymer, and can be controlled by adjusting the component ratio of PCL and PEG. The physical properties and degradability of the blends of PCL and its copolymer comprising PCL and PEG with polyolefins have been reported [6,7]. As blends of PCL and polyolefins are immiscible, compatibilization and modification of polyolefins are needed to minimize the interfacial tension and to improve adhesion between the dispersed phase and matrix of PCL/polyolefins blends.

One of degradable synthetic polymers that has been developed so far is aliphatic polyester, such as PCL $[8,9]$. PCL is very attractive due to its properties, such as a high permeability, the lack of toxicity, and also biodegradability $[10,11]$. PCL can be easily synthesized by ring-opening polymerization of $\varepsilon$-CL monomer in the presence of a complex distannoxane catalyst $[7,12]$. However, it has limited application because of low melting point $\left(60{ }^{\circ} \mathrm{C}\right)$, high crystallinity, and brittleness. The aim of the experiments is designed to improve the properties of PCL by formation of their polymers with 2,2-dimethyl-1,3-propandiol monomers and also to obtain polymers with various chain length size as a raw material to prepare poly(urethane-ester).

This paper presents the structure and properties of polymers P(CL-co-DP) prepared by a ring-opening polymerization between $\varepsilon$-caprolactone and 2,2dimethyl-1,3-propandiol monomers by using a distannoxane catalyst. The structure-property relationship of polymers were investigated by Fourier 
Transform Infrared (FTIR), Differential Scanning Calorimeter (DSC), ${ }^{1} \mathrm{H}$ and ${ }^{13} \mathrm{C}$ NMR spectroscopy, viscosity, and hydroxyl number.

\section{Experimental}

\subsection{Materials}

$\varepsilon$-caprolactone ( $\varepsilon$-CL) and 2,2-dimethyl-1,3-propandiol (DP) monomers were obtained commercially from Aldrich Chem. Co., and dried over $\mathrm{CaH}_{2}$ and distilled under a reduced pressure. Dibutyltin oxide $\left(\mathrm{C}_{4} \mathrm{H}_{9}\right)_{2} \mathrm{SnO}$ and dibutyltin dichloride $\left(\mathrm{C}_{4} \mathrm{H}_{9}\right)_{2} \mathrm{SnCl}_{2}$ as catalyst precursors were also obtained from Aldrich Chemical Co. 1-hydroxy-3-chlorotetrabutyl-distannoxane was prepared by reaction of dibutyltin oxide and dibutyltin dichloride in ethanol $95 \%$ [12].

\subsection{Preparation of Polymers}

1-hydroxy-3-chlorotetrabutyl-distannoxane $\left(1.2 \times 10^{-4} \mathrm{~mol}\right)$ in $5 \mathrm{~mL}$ hexane was first added to the reactor and then hexane was evaporated by heating in silicone oil bath at $80{ }^{\circ} \mathrm{C}$ under vacuum $\left(10^{-6} \mathrm{mmHg}\right)$ for 6 hours. Monomers of $\varepsilon^{-}$ caprolactone $(0.06 \mathrm{~mol})$ and 2,2-dimethyl-1,3-propandiol $(0.006 \mathrm{~mol})$ were added to the reactor at room temperature. The mixture was degassed during three freeze-thaw cycles and finally sealed under vacuum. Polymerization reactions were carried out at $100{ }^{\circ} \mathrm{C}$ for 4 hours. The resulting mixture was dissolved in chloroform $(100 \mathrm{~mL} / \mathrm{g}$ of initial monomer), and the polymer solution was stirred for 12 hours at room temperature and refluxed for 30 minutes. The clear solution was then concentrated $(10 \mathrm{~mL} / \mathrm{g}$ of initial monomer), followed by precipitation in diethyl ether to give a white solid of polymers. The same manner was done for other polymerizations with different composition of monomers (CL/DP =10/1, 20/1, 30/1, 40/1, and 50/1)

\subsection{Characterization of Polymers}

FTIR (Shimadzu 5800) was used to characterize chemical structure of polymers. The sample used in FTIR was in $\mathrm{KBr}$ pellet form. The ${ }^{1} \mathrm{H}$ NMR and ${ }^{13} \mathrm{C}$ NMR measurements were recorded at $400 \mathrm{MHz}$ and $100.5 \mathrm{MHz}$ on JEOL JNM-FX 400 spectrometer. The sample concentrations used in this measurement was typically $0.1 \% \mathrm{wt} / \mathrm{vol}$. NMR spectrum of the polymers was recorded at $25-30{ }^{\circ} \mathrm{C}$ with $\mathrm{CDCl}_{3}$ as solvent. Tetramethylsilane (TMS) was used as a reference. Differential Scanning Calorimeter (DSC) (General Du Pont 2000) was used to determine the thermal behavior of the polymers. All the scans were carried out from $-50^{\circ} \mathrm{C}$ to $250{ }^{\circ} \mathrm{C}$ at a heating rate of $10{ }^{\circ} \mathrm{C} \mathrm{min}^{-1}$. Molecular weights of polymers were determined by viscometer and ${ }^{1} \mathrm{H}$ NMR 
spectra. Hydroxyl number of polymers was determined by titration method according to ASTM method (D2849-69).

\section{Results and Discussion}

Preparation of polymers $\mathrm{P}(\mathrm{CL}$-block-DP) were done by ring-opening polymerization of $\varepsilon$-caprolactone (CL) and 2,2-dimethyl-1,3-propandiol (DP) monomers in the presence of complex distannoxane catalyst in the same condition with optimal condition for preparation of poly-(R,S)- $\beta$ hydroxybutyrate (PHB) by polymerization of $\beta-(\mathrm{R}, \mathrm{S})$-butyrolactone monomer $[8,13]$, as reaction shown in Figure 1.

The aim of this work is designed to improve the properties of PCL, especially high crystallinity and brittleness by formation of their polymers with 2,2dimethyl-1,3-propandiol, and also to obtain polymers with various chain length size, which will be used as a raw material to prepare poly(urethane-ester). In this paper is presented the influence of $\varepsilon$-caprolactone/2,2-dimethyl-1,3propandiol proportions on the structure and properties of polymers.<smiles>CC(C)(CO)CO</smiles>

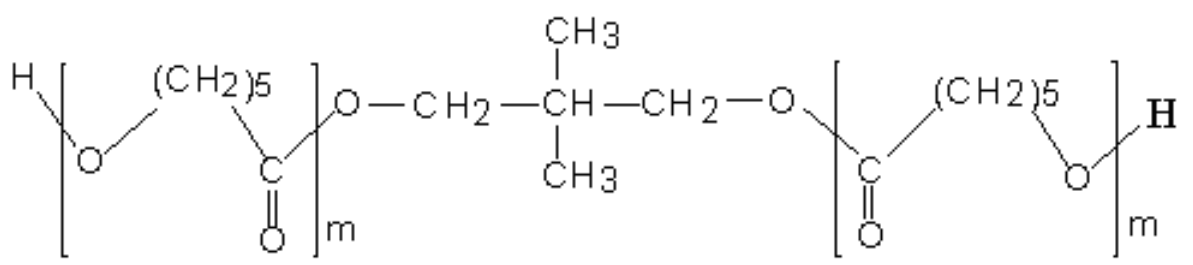

Figure 1 Scheme for the preparation of poly(E-caprolactone-block-2,2dimethyl-1,3-propandiol) in the presence of complex distannoxane catalyst.

FTIR spectra for polymers of $\varepsilon$-caprolactone and 2,2-dimethyl-1,3-propandiol monomers show the presence of superposition and displacement of characteristic peaks of each components (Figure. 2c). The peak intensity of hydroxyl group $(-\mathrm{OH})$ for polymers at wave number about $3440 \mathrm{~cm}^{-1}$ decreases significantly compared to that of hydroxyl group for 2,2-dimethyl-1,3propandiol monomer (Figure. 2a). These results indicate the presence of chemical reaction between hydroxyl group of 2,2-dimethyl-1,3-propandiol and 
carboxylate group $(-\mathrm{COOH})$ of $\varepsilon$-caprolactone to produce poly $(\varepsilon$-caprolactoneblock-2,2-dimethyl-1,3-propandiol) $\mathrm{P}(\mathrm{CL}-$ block-DP). The absorption peak of $\mathrm{OH}$ group in polymers is attributed by hydroxyl group in the end of polymer chain, and each polymer chain has two hydroxyl groups bound in the end of polymer chain as showed in Figure.1.
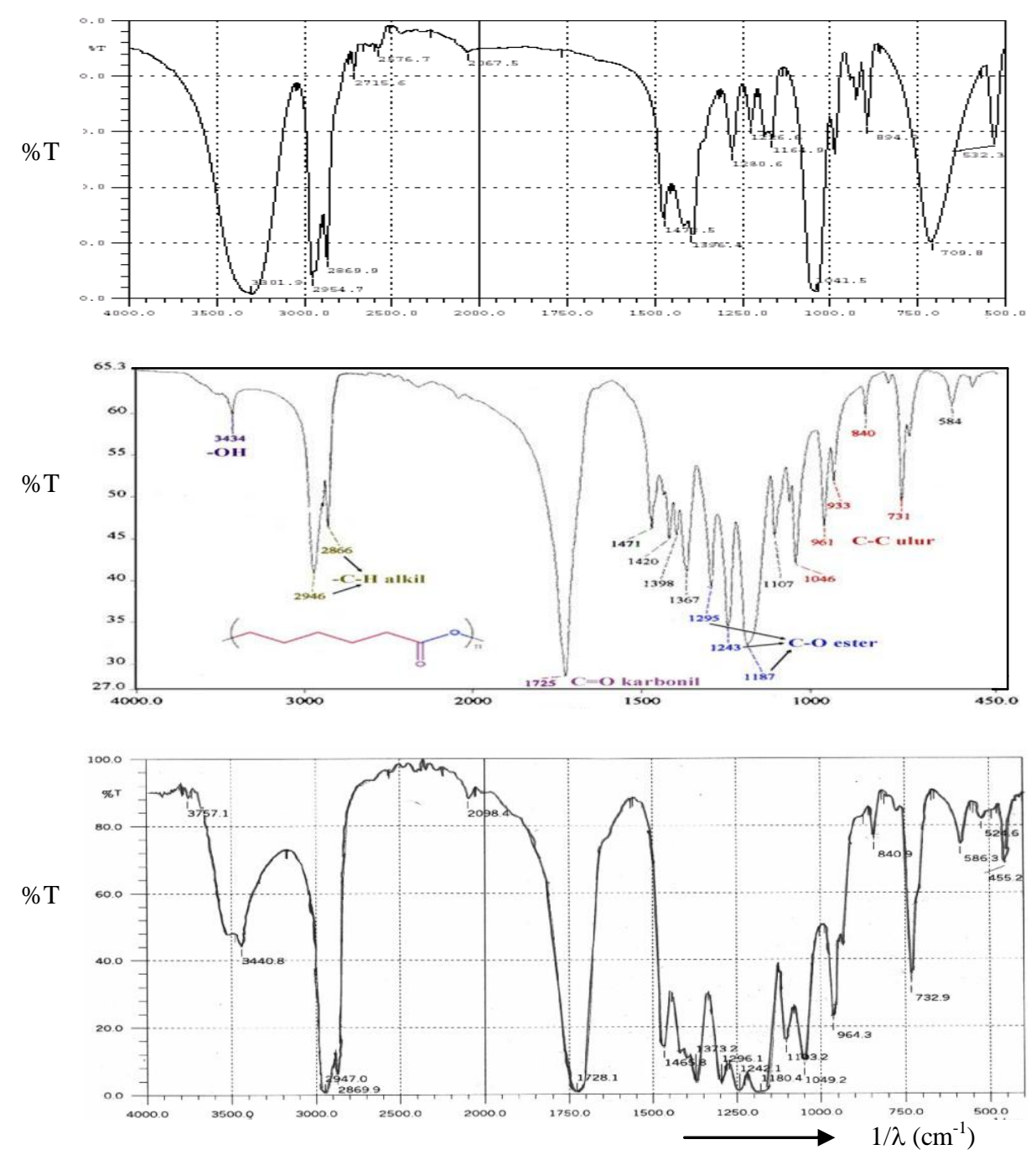

Figure 2 FTIR Spectra of: a). 2,2-dimethyl-1,3-propandiol, b). poly( $\varepsilon$ caprolactone), and c). Poly( $\varepsilon$-caprolactone-block-2,2-dimethyl-1,3-propandiol) with CL/DP ratio of 30/1 
Table 1 The ratio of the absorption intensity of hydroxyl and carbonyl groups to that of methyl group at wave number of $2870 \mathrm{~cm}^{-1}$ of polymers.

\begin{tabular}{ccccc}
\hline No & $\begin{array}{c}\text { Monomer ratio } \\
\text { CL/DP }\end{array}$ & $\begin{array}{c}\text { Polymer ratio }^{\mathbf{b})} \\
\text { PCL/DP }\end{array}$ & $\begin{array}{c}\text { Intensity ratio }^{\mathbf{c})} \\
-\mathbf{O H} / \mathbf{C H}_{\mathbf{3}}\end{array}$ & $\begin{array}{c}\text { Intensity ratio }^{\mathbf{c})} \\
-\mathbf{C O}-/ \mathbf{C H}_{\mathbf{3}}\end{array}$ \\
\hline 1 & $10 / 1$ & $9 / 1$ & 0.53 & 1.06 \\
2 & $20 / 1$ & $17 / 1$ & 0.44 & 1.09 \\
3 & $30 / 1$ & $29 / 1$ & 0.38 & 1.21 \\
4 & $40 / 1$ & $36 / 1$ & 0.29 & 1.79 \\
5 & $50 / 1$ & $41 / 1$ & 0.33 & 1.69 \\
6 & CL $(0.06$ mol) & $100 / 0$ & 0.05 & 3.90 \\
\hline${ }^{a}$ Monomer compositions (in mol ); ${ }^{\text {b) }}$ Polymer compositions (in mol) determined by ${ }^{1} \mathrm{H} \mathrm{NMR}$ \\
spectroscopy; ${ }^{\text {c) }}$ Absorption intensity ratio determined by FTIR spectroscopy.
\end{tabular}

Furthermore, it was observed that the absorption peak intensity of hydroxyl group $(-\mathrm{OH})$ at wave number of $3440 \mathrm{~cm}^{-1}$ decreased with increasing $\varepsilon^{-}$ caprolactone composition in polymers, whereas the absorption peak intensity of carbonyl group (-CO-) group at wave number of $1728 \mathrm{~cm}^{-1}$ increased. The quantitative ratios of the absorption intensity of hydroxyl $\left(3440 \mathrm{~cm}^{-1}\right)$ and carbonyl groups $\left(1728 \mathrm{~cm}^{-1}\right)$ to that of methyl group $\left(-\mathrm{CH}_{3}\right)$ at wave number of $2870 \mathrm{~cm}^{-1}$ of polymers in various compositions of $\varepsilon$-CL monomer were determined by measurement of absorption intensity in FTIR spectra as shown in Table 1.

The ratios of the absorption intensity of hydroxyl group in polymers decrease significantly with increasing $\varepsilon$-caprolactone composition in polymers, whereas the ratios of the absorption intensity of carbonyl group increase. In addition, the absorption intensity ratios of hydroxyl and carbonyl groups to that of methyl group for pure PCL without addition of 2,2-dimethyl-1,3-propandiol were calculated about 0.05 and 3.90, respectively. These results are caused by the increase of $\varepsilon$-caprolactone monomer bound in polymer chain producing polymers with longer chain length. This is supported by the increasing intrinsic viscosity and molecular weight of polymers with the increasing CL monomer composition used in polymerization (Table 2). For more detail structure analysis was carried out chemical structure analysis by ${ }^{1} \mathrm{H}$ and ${ }^{13} \mathrm{C}$ NMR spectroscopy.

${ }^{1} \mathrm{H}$ and ${ }^{13} \mathrm{C}$ NMR spectrum of poly(2,2-dimethyl-1,3-propandiol-co- $\varepsilon$ caprolactone) are shown in Fig. 3 and 4, respectively. Resonance peak distributions of proton observed in ${ }^{1} \mathrm{H}$ NMR spectra for polymers are as follows : 0.83-0.92 ppm for methyl hydrogen $\left(\mathrm{CH}_{3}\right)(\mathrm{f}), 1.55-1.68 \mathrm{ppm}$ for $\mathrm{CH}_{2}(\mathrm{~b}), 2.25-$ $2.35 \mathrm{ppm}$ for $\mathrm{CH}_{2}(\mathrm{~d}), 3.56-3.62 \mathrm{ppm}$ for $\mathrm{CH}_{2}(\mathrm{e})$, and 3.98-4.07 ppm for $\mathrm{CH}_{2}(\mathrm{a})$. The resonance peak distributions of carbon observed in ${ }^{13} \mathrm{C}$ NMR spectra for polymers are as follows : $22.0 \mathrm{ppm}$ for methyl carbon $\left(\mathrm{CH}_{3}\right)(\mathrm{h}), 24.5 \mathrm{ppm}$ for $\mathrm{CH}_{2}(\mathrm{c}), 25.2 \mathrm{ppm}$ for $\mathrm{CH}_{2}(\mathrm{~d}), 28.3 \mathrm{ppm}$ for $\mathrm{CH}_{2}(\mathrm{~b}), 32.2 \mathrm{ppm}$ for $-\mathrm{C}(\mathrm{i}), 34.1$ 
ppm for $\mathrm{CH}_{2}(\mathrm{e}), 62.5 \mathrm{ppm}$ for $\mathrm{CH}_{2}(\mathrm{~g}), 64.1 \mathrm{ppm}$ for $\mathrm{CH}_{2}(\mathrm{a})$, and $173.5 \mathrm{ppm}$ for carbonyl carbon (-CO). The distributions of resonance peaks in ${ }^{1} \mathrm{H}$ and ${ }^{13} \mathrm{C}$ NMR spectrum indicate that polymerization of $\varepsilon$-caprolactone and 2,2dimethyl-1,3-propandiol monomers in the presence of distannoxane catalyst produce block polymers with the chain structure as proposed in reaction above (Figure 1).

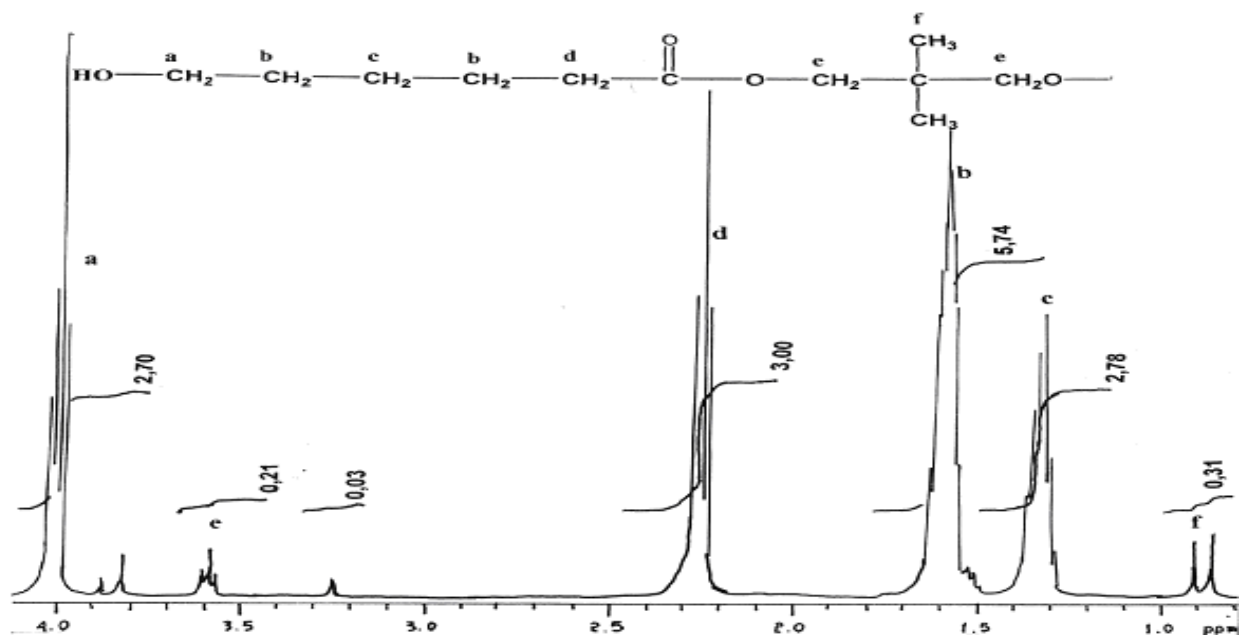

Figure $3{ }^{1} \mathrm{H}$ NMR spectra of poly( $\varepsilon$-caprolactone -block-2,2-dimethyl-1,3propandiol).

${ }^{1} \mathrm{H}$ NMR spectroscopy was used to determine compositions of each components in polymers by integration of resonance peak intensity of methylene hydrogen $\mathrm{CH}_{2}$ (c) of $\mathrm{CL}$ component at chemical displacement of $2.25 \mathrm{ppm}$ and methyl hydrogen $\left(\mathrm{CH}_{3}\right)$ of 2,2-dimethyl-1,3-propandiol component at $0.90 \mathrm{ppm}$ (Figure 3). The PCL component composition in polymers increases with the increase of CL monomer compositions used in polymerization as shown in Table 2. However, the PCL component composition in polymers is slightly lower than the initial composition of CL monomer, and the difference between the composition of PCL component in polymers and the initial composition of $\mathrm{CL}$ monomer increases with the increasing CL monomer composition used in polymerization. This result might be attributed by the lower reactivity of CL monomer to react with active site of polymers with longer chain length due to the presence of polymer chain folding, so that active site of polymers with longer chain length in its chain propagation is more difficult reacted with CL monomer. 
The melting points of polymers by using a differential scanning calorimeter (DSC) in various proportions of CL monomer are described in Table 2.The melting point of polymers increases from 56.6 to $79.5^{\circ} \mathrm{C}$ with increasing CL monomer compositions used in polymerization, while the melting point of pure PCL reported in previous paper is $74.7^{\circ} \mathrm{C}$ with high crystalline structure [7].

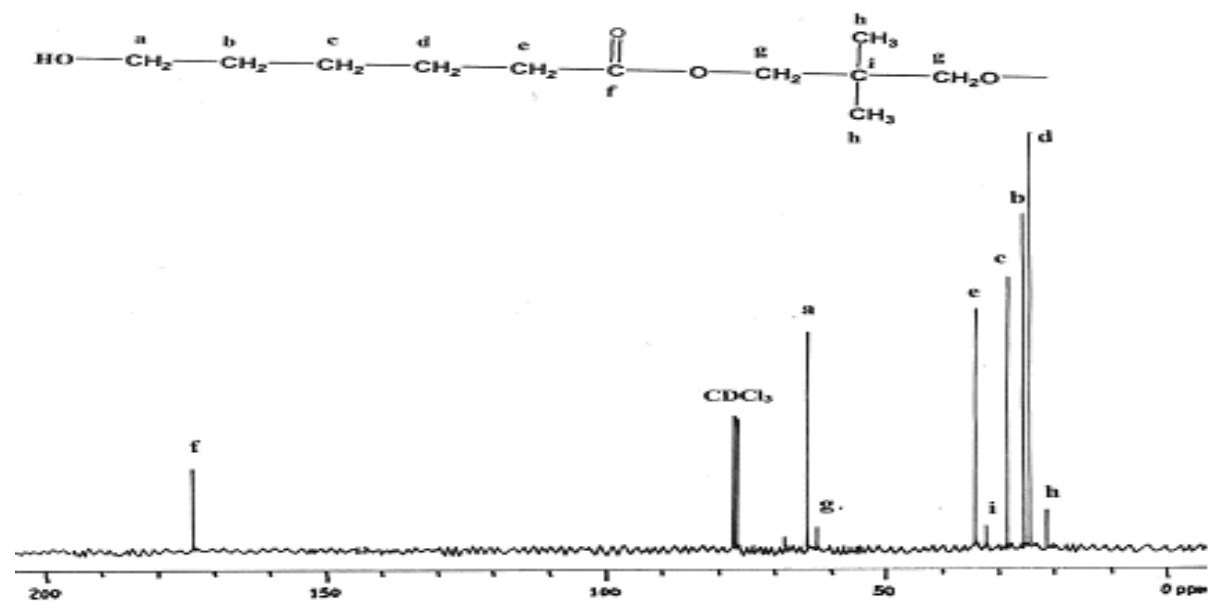

Figure $4{ }^{13} \mathrm{C}$ NMR spectra of Poly( $\varepsilon$-caprolactone-block-2,2-dimethyl-1,3propandiol).

Table 2 Characteristics of the polymers synthesized by polymerization of 2,2dimethyl-1,3-propandiol and $\varepsilon$-caprolactone in the presence of distannoxane catalyst

\begin{tabular}{|c|c|c|c|c|c|c|c|}
\hline $\begin{array}{l}\mathrm{N} \\
\mathrm{o}\end{array}$ & $\begin{array}{l}\text { Mol ratio } \\
\text { CL/DP }\end{array}$ & $\begin{array}{l}\text { Mol ratio } \\
\text { PCL/DP }\end{array}$ & $\mathrm{Mn}^{\mathrm{c})}$ & $\begin{array}{c}\text { Polymer } \\
\text { phase }\end{array}$ & $\begin{array}{l}\left.\mathrm{Tm}^{\mathrm{f}}\right) \\
\left({ }^{\circ} \mathrm{C}\right)\end{array}$ & $\begin{array}{c}{[\eta]^{\mathrm{d})}} \\
\mathrm{x} \quad 10^{-3}\end{array}$ & $\begin{array}{l}\text { Hydroxyl } \\
\text { number }^{\mathrm{e}}\end{array}$ \\
\hline 1 & $10 / 1$ & $9 / 1$ & 1240 & Gel & 56.6 & 45.4 & 219.5 \\
\hline 2 & $20 / 1$ & $17 / 1$ & 2380 & Pasta & 60.5 & 51.8 & 215.2 \\
\hline 3 & $30 / 1$ & $29 / 1$ & 3520 & Soft solid & 64.4 & 73,1 & 172.2 \\
\hline 4 & $40 / 1$ & $36 / 1$ & 4660 & Soft powder & 68.7 & 84.7 & 161.8 \\
\hline 5 & $50 / 1$ & $41 / 1$ & 5800 & Powder & 79.5 & 95.6 & 119.5 \\
\hline 6 & $\mathrm{CL}(0.06 \mathrm{~mol})$ & PCL & 3850 & Hard powder & 74.7 & 75.5 & 165.0 \\
\hline
\end{tabular}

Reaction condition : Mol ratio of CL/catalyst $=500$, Mol of $\mathrm{CL}=0.06 \mathrm{~mol}(6.84 \mathrm{~g})$,

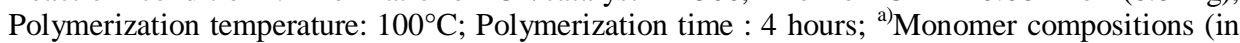

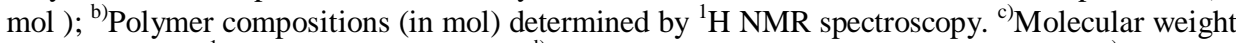
determined by ${ }^{1} \mathrm{H}$ NMR spectroscopy, ${ }^{\mathrm{d})}$ Intrinsic viscosity in chloroform solvent. ${ }^{\mathrm{e})} \mathrm{Hydroxyl}$ number determined by titration with $\mathrm{KOH},{ }^{\mathrm{f}}$ Melting point determined by DSC.

These results indicate that the addition of 2,2-dimethyl-1,3-propandiol in polymerization can disturb the polymerization of CL monomer to produce polymer with lower molecular weight, thermal properties, and crystalline structure (Table 2). However, the higher CL/DP ratios result in polymers with higher molecular weights and melting points, whereas their brittleness of 
polymers decrease compared to the brittleness of pure PCL. This result was proven by the difficulty of pure PCL to form polymer films, but the polymer obtained by polymerization of CL monomer with addition of 2,2-dimethyl-1,3propandiol can be easily formed polymer films. Furthermore, the hydroxyl number of polymers decreases with the increase of CL compositions. This result may be associated to the structure of polymers to become more regular and denser with increasing the chain length of PCL sequence in polymers. The decrease of hydroxyl number of polymers is related to the decrease ratio of hydroxyl group (-OH) to chain length of polymers. The hydroxyl group of polymers is only in the end of polymer chain, and each polymer chain has two hydroxyl groups bound in the end of polymer chain, whereas the chain length of polymers increases with increasing PCL sequence in polymers. These results also supported the previous analysis that it was occurred the formation of block polymers between $\varepsilon$-caprolactone monomer and 2,2-dimethyl-1,3-propandiol in the presence of complex distannoxane catalyst.

\section{Conclusion}

Polymerization of 2,2-dimethyl-1,3-propandiol and $\varepsilon$-caprolactone monomers in the presence of 1-hydroxy-3-chloro-tetraisobuthyldistanoxane as a catalyst produced block polymers with various chain length depend on CL/DP ratio used in polymerization. The higher CL/DP ratios result in polymers with higher molecular weights and melting points, whereas their brittleness of polymers decrease compared to that of pure PCL. The hydroxyl number of polymers decreases with the increase of CL compositions. The reactivity of CL monomer decreases to the active site of polymers with longer chain size. The presence of polymer chain folding leads the active site of polymers to be difficult reacted with CL monomer.

\section{Acknowledgements}

The authors gratefully acknowledge funding support from the Research Grant of Competition Research Program under the Directorate of Higher Education, Department of National Education, the Republic of Indonesia and the Institute for Research-LPPM, Institut Teknologi Bandung with Contract No. 013/SP2H/PP/DP2M/III/2007.

\section{References}

[1] Arslan, H., Mentes, A., Hazer, B., Synthesis and Characterization of Di, Tri and Multiblock Polymers Containing Poly(3-Hydroxy Butyrate Unit, J. Appl. Polym. Sci., 94, 1789, 2004. 
[2] Hazer, B., Lenz, R.W., Cakmakli, B., Borcakli, M., and Kocer, H., Preparation of poly(ethylene glycol) grafted poly(3-hydroxyalkanoate)s, Macromol Chem Phys., 200, 1903, 1999.

[3] Malin, M., Vainio, M. H., Karjalainan, T., Seppala, J., Biodegradable Lactone Polymers. II : Hydrolytic Study of E-Caprolactone and Lactide Polymers, J. Appl. Polym. Sci., 59, 1289, 1996.

[4] Koyama, N., Doi, Y., Miscibility, Thermal Properties, and Enzymatic Degradability of Binary Blends of Poly(R)-3-Hydroxy Butyric Acid with Poly( $\varepsilon$-Caprolactone-Co-Lactide), Macromolecules, 29, 5843, 1996.

[5] Wang, S.G., Qiu, B., Polycaprolactone-Poly(Ethylene Glycol) Block Copolymer: (I) Synthesis and Degradability In Vitro, Polym. Adv. Technol., 4, 363, 1993.

[6] Iwamoto, A., Tokiwa, Y., Effect of The Phase Structure on Biodegradability of Polypropylene /Poly-E-Caprolactone Blends, J. Appl. Polym. Sci., 52, 1357, 1994.

[7] Arcana, I M., Bundjali, B., Yudistira, I., Jariah, B., Sukria, L., Study on Properties of Polymer Blends from Polypropylene with Polycaprolactone and Their Biodegradability, Polymer J., 39, 1337, 2007.

[8] Arcana, I M., Giani-Beaune, O., Schue, R., Schue, F., Amass, W., Amass, A., Ring-Opening Copolymerization of Racemic $\beta$-Butyrolactone with $\varepsilon$ Caprolactone and $\delta$-Valerolactone by Distannoxane Derivative Catalysts: Study of The Enzymatic Degradation in Aerobic Media of Obtained Polymers, Polym Int., 51(10), 859, 2002.

[9] Lisuardi, A., Schoenber, A., Gada, M., Gross, R. A., McCarthy, S. P., Biodegradation of Blends of Poly- $\beta$-hydroxybutyrate and Poly- $\varepsilon-$ caprolactone, Polym. Mater. Sci. Eng., 67, 298, 1992.

[10] Vion, J. M., Jerome, R., Teyssie, Ph., Aubin, M., Prud'homme, R.E., Synthesis, Characterization and Miscibility of Caprolactone Random Polymers, Macromolecules, 19, 1828, 1986.

[11] Brode, G. L., Koleske, J. V., Lactone Polymerization and Polymer Properties, J. Macromol. Sci. Chem., A6, 1109, 1972.

[12] Otera, J., Dan-Oh, N., Nosaki, H., Novel Template Effects of Distannoxane Catalysts in Highly Efficient Transesterification and Esterification, J. Org. Chem., 56, 5307, 1991.

[13] Arcana, I M., Sulaeman, A., Pandiangan, K.D., Handoko, A., Ledyastuti, M., Synthesis of Polyblends from Polypropylene with Poly $(R, S)-\beta$ Hydroxybutyrate and Its Characterization, Polym Int., 55, 435, 2006. 